\title{
Bernardino Ramazzini (1633-1714): an often forgotten pioneer in maritime health
}

\author{
Elisa Galimberti, Francesco Manzini, Michele A. Riva
}

Section of History of Medicine, University of Milano-Bicocca, Monza, Italy

As known, the Scottish physician James Lind (1716-1794) was one of the first scholars who focused on health condition of seamen in his renowned work "An essay on the most effective means of preserving the health of seamen" (1762) [1]. Actually, a few decades before Lind, the Italian physician Bernardino Ramazzini (1633-1714), universally credited as the founder of occupational health, was also a pioneer in describing some basic principles of maritime health [2]. In the first edition of "De Morbis Artificum" (Modena, 1700), Ramazzini devoted a chapter to the diseases of fishermen ("De piscatorum morbis"). According to the Italian physician, their health had to be protected by community, since their work was fundamental in "supplying food and delights to the tables. (...) Indeed the earth alone would not be able to nourish man if the sea did not assist with its abundant supply of fish" [3]. He postulated that health of these workers was mainly influenced by bad weather conditions (freezing cold in winter and scorching heat in summer). Since "fishermen [were] always wearing wet clothes", obstruction of transpiration would cause pleurisy, pneumonia, cough and air hunger. Furthermore, Ramazzini evidenced a high frequency of leg ulcers that were difficult to heal, since fishermen spent their time in damp spaces [3]. After the publication of the first edition of "De Morbis Artificum", Ramazzini was appointed as a professor at the prestigious University of Padua; this city was a part of the Republic of Venice, which had always took great interest in navigation and sea trades. This was probably the main reason that led the Italian physician to further development of the maritime health topic and adding a new chapter about diseases of sailors and oarsmen (De nautarum et remigum morbis) in the new edition of "De Morbis Artificum" (Padua, 1713).
According to Ramazzini, poor food quality, sleepless nights and non-potable water generally worsened heath conditions, triggering epidemics. Sailors were more susceptible to get chronic diseases, aggravated by the environment where they lived, while oarsmen suffered more from acute crisis, which often ended with death. Their cruet diet of "salted meat, worm-eaten sea-biscuits and half-putrid water [made] patient's humours resistant to common remedies", so they needed stronger dosages of drugs to cure them [3]. In a modern way, he also correlated lice and bugs infestation to the lack of personal hygiene among the sailors, since there was not even "enough water to wash their faces and hands" [3]. Finally, Ramazzini concluded this chapter stating that "sailors and all those who spent their lives at sea seldom live to a ripe old age, as with those in military camp" [3]. Even if we do not know if Lind ever got in touch with Ramazzini's work, both of them underlined the importance of observing and investigating the aetiology of pathologies in order to cure them, contributing to the birth of maritime health [2]. Therefore recalling the role of Bernardino Ramazzini in the development of this discipline appears as a necessary acknowledgement, since this year the $300^{\text {th }}$ anniversary of his death is celebrated [4].

\section{REFERENCES}

1. Tröhler U. Lind and scurvy: 1747 to 1795 . J R Soc Med 2005; 98 : 519-522.

2. Riva MA, Bonifaci G, Cesana G. La salute e la sicurezza dei lavoratori del mare: note storiche. G Ital Med Lav Erg 2013; 35: 4 (suppl.): 40.

3. Ramazzini B. Works. Carnevale F, Mendini M, Moriani G (eds). Cierre edizioni, Verona 2009.

4. Franco G. A tribute to Bernardino Ramazzini (1633-1714) on the tercentenary of his death. Occup Med (Lond) 2014; 64: 2-4. 